\title{
Malaria prevalence and incidence in an isolated, meso- endemic area of Mozambique
}

Jacques Derek Charlwood, Erzelia V.E. Tomás, Mauro Bragança, Nelson Cuamba, Michael Alifrangis, Michelle Stanton

Isolated areas, such as the $2 \times 7 \mathrm{~km}$ peninsula of Linga Linga in Mozambique, are the places where malaria might be most easily eliminated. Currently available control strategies include long-lasting insecticidal bed nets impregnated with pyrethroid insecticides (LLINs), rapid diagnostic tests (RDTs) for diagnosis and artemisinin combination therapy (ACT) for treatment and these were applied on the peninsula. In 2007, following a census of the population and mapping of 500 households, five annual all age prevalence surveys were conducted. Information on LLIN use, house construction, and animal ownership was obtained. A spatially structured generalized additive model indicated that malaria risk was greatest towards the northern end of the peninsula and that people living in houses with grass or thatch roofs had a greater risk of malaria than those living in houses with corrugated iron roofs. Incidence peaked nine weeks after rainfall $\left(r^{2}=0.34, p=0.0002\right)$. From 2009 incidence was measured at a centrally based project clinic. The proportion of under nine year old resident attendees diagnosed with malaria decreased significantly from $48 \%$ in 2009, to $35 \%$ in 2010 and $25 \%$ in 2011 . At the same time there was a shift in the peak age of cases from 1-4 year olds to 5-9 year olds. Nevertheless, in order to further reduce malaria transmission in an area such as Linga Linga additional vector control measures need to be considered. 
2 Malaria prevalence and incidence in an isolated, meso-endemic area

3 of Mozambique

5 JD Charlwood, EVE Tomás, M Bragança, N Cuamba, M Alifrangis, M Stanton

\section{Abstract}

Isolated areas, such as the $2 \times 7 \mathrm{~km}$ peninsula of Linga Linga in Mozambique, are the places where malaria might be most easily eliminated. Currently available control strategies include long-lasting insecticidal bed nets impregnated with pyrethroid insecticides (LLINs), rapid diagnostic tests (RDTs) for diagnosis and artemisinin combination therapy (ACT) for treatment and these were applied on the peninsula. In 2007, following a census of the population and mapping of 500 households, five annual all age prevalence surveys were conducted. Information on LLIN use, house construction, and animal ownership was obtained. A spatially structured generalized additive model indicated that malaria risk was greatest towards the northern end of the peninsula and that people living in houses with grass or thatch roofs had a greater risk of malaria than those living in houses with corrugated iron roofs. Incidence peaked nine weeks after rainfall $\left(\mathrm{r}^{2}=0.34, \mathrm{p}=0.0002\right)$. From 2009 incidence was measured at a centrally based project clinic. The proportion of under nine year old resident attendees diagnosed with malaria decreased significantly from $48 \%$ in 2009 , to $35 \%$ in 2010 and $25 \%$ in 2011 . At the same time there was a shift in the peak age of cases from 1-4 year olds to 5-9 year olds. Nevertheless, in order to further reduce malaria transmission in an area such as Linga Linga additional vector control measures need to be considered.

\section{Background}

Malaria remains a serious problem in Mozambique. According to UNICEF it is the leading killer of children, contributing to around 33\% of all child deaths. Overall more deaths have been attributed to it (28.8\%) than to any other single cause, including HIV/AIDS [www.unicef.org/mozambique/child_survival_2933.html]. Figures like these, from many

31 areas of Africa, have led to major funding initiatives directed towards its control. These 
32 have met with considerable success, much of which has occurred through widespread use

33 of Long Lasting Insecticidal Nets (LLINs) for prevention, and the use of highly effective

34 drugs, the artemisinin-based combination therapies (ACTs), for treatment. These successes

35 have prompted the idea that the disease can locally be eliminated, eventually leading to its

36 global eradication.

37

38 Isolated areas, such as islands and peninsulas, that are surrounded by mosquito-hostile

39 environments, be that sea, desert or uninhabited land, are the places most susceptible to

40 malaria elimination. In such places there is much less immigration and emigration of

41 vectors (and people) than in more connected environments (Aregawi et al., 2011,

42 Hagmann et al., 2003, Ishengoma et al., 2013, Pinto et al., 2003, Lucas 2010, Lum et al.,

43 2007, Sudomo et al, 2004, Teklehaimanot et al., 2010). The sandy, low altitude peninsula of

44 Linga Linga, $500 \mathrm{~km}$ north of Maputo, is such an isolated area, since, apart from a $2 \mathrm{~km}$

45 stretch of uninhabited land at the narrow neck, it is surrounded by saline water making it a

46 virtual ecological island.

In 2007, a project to determine the impact on malaria of introducing currently available control strategies, including LLINs and treatment with ACT's (artemether-lumefantrine, AL,

50 according to national guidelines), was implemented on the peninsula. Due to the delayed

51 acquisition of immunity the mean age of maximum prevalence may increase, although

52 prevalence itself may not change (Smith et al., 1993). A decrease in incidence and a shift

53 towards older age groups falling ill are, however, more sensitive measures of changes in

54 transmission than estimates of prevalence. Incidence was therefore monitored from 2009- 
552011 in a clinic established by the project whilst prevalence for the years 2007-2011 was

56 monitored in annual all age prevalence surveys.

57

58 An understanding of risk factors for malaria can guide novel, possibly site specific, control

59 measures to be used in places like Linga Linga. Possible risk factors were, therefore,

60 examined. Both spatial and temporal analysis of the data was undertaken, and the results

61 are discussed in relation both to the effect that the interventions had on malaria

62 transmission and to possible additional control techniques that might be applied on the 63 peninsula.

65 Methods

66

67 Linga Linga $\left(23^{\circ} 43^{\prime} 1.29^{\prime \prime} \mathrm{S}, 35^{\circ} 24^{\prime} 15.04 " \mathrm{E}\right)$, which lies $6 \mathrm{~km}$ to the east across the 68 Morrumbene Bay opposite the district capital Morrumbene, has been described by 69 Charlwood et al., (2013) and Thomsen et al. (2013) and appears on a number of websites.

70 People are involved in fishing and the production of copra or the artisanal manufacture of 71 raffia baskets, hats and bags. A number of tourist lodges, employing non-resident and local 72 labour, have been built in recent years or are under construction. At the time of the initial 73 survey there was no health centre on the peninsula, the nearest health centres being in the 74 village of Coche, five km to the north of Linga Linga, or in Morrumbene itself (Fig 1).

75 Anopheles funestus is the only malaria vector on the peninsula. During the long dry season, 76 the mosquito may become gonotrophically discordant and individual mosquitoes may 
77 survive for long periods, taking several blood meals without laying eggs. Thus, despite low

78 numbers of mosquitoes, transmission continues (Charlwood et al., 2013).

At the start of the project all residents were censused, informed of the purpose of the study and consent to participate was obtained; houses were mapped (with Garmin e-Trex hand held global positioning system (GPS) receiver units) and numbered. House dimensions and manner of construction were noted.

\section{Risk factors examined}

86

Since the mosquitoes in Linga Linga may be gonotrophically discordant (Charlwood et al., 2103) they may feed where they rest (as well as rest where they feed), increasing exposure.

The kind of roof that covers a house may influence the likelihood of the vector resting inside (Kirby et al., 2005). Roofs and walls were categorized by whether the materials they were made from were 'natural' materials (reed, palm leaf, grass, palm frond), or 'manmade' ones, such as corrugated iron, bricks or tiles. Other possible risk factors recorded were the number of animals kept by householders, age and number of residents, bednet ownership, the duration of residency and sources of drinking and washing water

95 (separated into 'in the house', 'from a well' or 'neighbours').

\section{Interventions}

In 2007 the fifteen households with more than two children below ten years of age received two nets and 100 of the remaining 141 households with children a single net. In this case households with the youngest children were given priority. In 2008, two days 
101 prior to the prevalence survey, a further 500 LLINs were distributed.

102 In March 2009 a clinic was established in an unused cement house in a central location (Fig

103 1). The clinic was open from Monday to Friday in the mornings, with a resident nurse also

104 available for emergency consultations at other times.

105

Prevalence surveys

107

108 The sampling selection was similar to that described in Smith et al., (1993). Following the

109 initial census, in February 2007, residents were invited to attend an all-age baseline

110 malaria prevalence survey. Subsequent surveys were conducted in February 2008, March

1112009 , April 2010 and June 2011.

112

113 Seven locations were chosen as survey field sites. Local residents were informed the day

114 prior to the survey that it would be taking place, and invited to come to the site location to

115 be surveyed. In addition, a survey was undertaken at the school to collect data of school-

116 aged children who had not been previously screened. During the surveys, residents were

117 asked if they had experienced malaria since the start of the year and where they went for

118 treatment. In addition to these questions in the initial survey (2007), information on

119 absence from the peninsula, duration, location, means of transport and whether they had

120 used a net when away, was also collected. In subsequent surveys, people were asked (in

121 the local language): 1 . 'How long have you lived in your present house?' 2. 'Where did you

122 come from?' 3. 'Do you have a mosquito bednet?' 4. 'Did you sleep under it last night?' and

123 5. 'Where did you obtain your net?' Thus, the parasitology datasets contained information 
124 on the individual's house number, name, age, sex, whether or not they tested positive for

125 malaria, and whether or not they used a bednet the previous night.

126

127 In all surveys finger prick blood was used in the preparation of thick and thin blood films.

128 Films were stained with 5\% Giemsa for 20 minutes and examined at the National Reference

129 Laboratory in Maputo for the presence of parasites. Slides were read twice and numbers of

130 parasites per 500 leucocytes were counted and converted to densities per micro-litre of

131 blood, assuming a density of 8000 leucocytes per micro-litre (Bruce-Chwatt, 1985).

132 Parasite density per micro-litre of blood was determined according to the formula:

133

134 Density $=([$ P.f Count $] *[8000]) /[$ White Blood Cell Count $]$

135

136 People's temperature was also taken. In surveys from 2008 onwards, a malaria Rapid

137 diagnostic test, RDT (OptiMal $®$ ) was given to anyone with a fever (defined as an axillary

138 temperature of $>37.5{ }^{\circ} \mathrm{C}$ ). Those that tested positive by RDT were treated with AL

139 according to national guidelines.

140 Incidence data

141

142 The age, sex and house number or resident status (resident or visitor) of attendees to the

143 clinic was recorded over the period March 2009 - May 2011. Attendees were asked how

144 long they had had their symptoms, including headache and fever and whether they had

145 slept under a bednet the previous night.

146 
147 When they were available RDTs were used to determine if patients reporting with

148 symptoms and/or fever had malaria. At the same time (also when RDTs were not

149 available), a blood slide was taken and subsequently read for parasite confirmation. Thick

150 and thin blood films were prepared of diagnosed cases and subsequently read by a

151 microscopist in Morrumbene. Parasite density was, however, not determined. In the

152 absence of RDTs treatment was, therefore, based on clinical diagnosis, which was

153 subsequently checked by microscopy. People with parasites confirmed by RDT, or

154 presumptively diagnosed with malaria when RDTs were not available, were treated with

155 AL.

156 Rainfall data

157

158 Daily rainfall data from the town of Maxixe, approximately $15 \mathrm{~km}$ from Linga Linga, kindly

159 provided by the Rio-Sul water management project, were used to compare incidence rates

160 with rainfall. Although it rains less on Linga Linga than it does in Maxixe, the relative

161 difference between years is still likely to occur.

162 Data analysis

163

164 Data was entered into MS Excel spreadsheets and analysed with the software R (R Core

165 Team, 2013). Summaries of the 2007 census data were produced, including the age

166 distribution of the population and bednet ownership and use by sex. Prevalence surveys

167 (2007-2011) were matched with the census data using the unique household ID number

168 (additional file 1) which enabled overall annual malaria prevalence to be tabulated, and

169 household-level malaria prevalence to be mapped using the software ArcGIS. Annual 
170 prevalence and the geometric mean parasite density by age group $(<1,1-4,5-9,10-19,20-$

$17129,>29$ ) were calculated to assess whether there was any evidence of a change in the age

172 distribution of cases. An individual-level multiple logistic regression model was fitted to the

173 prevalence data, with potential risk factors under consideration including age group,

174 bednet usage and household characteristics (roof type, door type, distance to the clinic,

175 number of people, water and sanitation access). A backwards stepwise model selection

176 approach based on minimising the Akaike Information Criterion (AIC) was used to

177 determine which variables to include in the final model. A generalised additive model

178 (GAM) was then fitted to the data by adding a spatially smooth term to the final model to

179 account for any possible residual spatial dependency in the data, and a map of this term 180 was produced.

181

182 Summaries of the percentage of clinic attendees who were diagnosed with, or tested for, 183 malaria were calculated by age group, sex, resident status (resident or non-resident),

184 reporting year, and bednet usage. Chi-squared tests were performed in order to elucidate

185 whether there was an association between malaria risk and these variables. The straight-

186 line distance between households and the clinic was calculated using ArcGIS, and the

187 correlation between the number of visits per person per household and distance to the

188 clinic was calculated to assess whether people living further away were less likely to seek 189 treatment.

190

191 Ethics

192 
193 The project received ethical clearance from the National Bioethics Committee of

194 Mozambique (reference 123/CNBS/06) on the 2nd of August 2006.

195 Results

196 Population composition

197

198 There were 467 households recorded in the census of 2007. A further 33 houses were

199 recorded early in 2008 giving a total of 500. The locations of the households are presented

200 in Figure 1. The age distribution of the population is given in Table 1. Table 1 also provides

201 data on the age of the study population and the ages of residents and non- residents

202 attending the clinic. Of the 195 households recorded in the census of 2007 with resident

203 children less than 15 years of age, 118 had only one child, 46 had two children, 21 had

204 three children, nine had four and one house had five children. Five point seven per cent

$205(5.7 \%)$ of the population was between 55 and 64 years of age and 9.1\% was over 65 years

206 of age (compared to a national average of $3.5 \%$ and $2.9 \%$ respectively derived from

207 www.theodora.com, $\mathrm{z}$ test $\mathrm{p}<0.05)$.

208

209 At the start of the study only 183 (19\%) people from 58 (12\%) households used a bednet.

210 Bednet use was equally divided amongst the 447 males and 528 females. Of the 410 people

211 who completed the baseline prevalence survey in 2007, $163(40 \%)$ had been out of Linga

212 Linga in the previous year. Of these, 146 had left by boat, five had gone by foot and only

213 three had travelled by car. The majority of people who reported that they had been absent

214 from the peninsula in the previous year had only spent one or two nights away. 
216 Prevalence and density of malaria parasites 2007-2011

217

218 An overview of the parasitology datasets, including the number of individuals per survey,

219 and the number of individuals that matched the 2007 census data, is presented in Table 2.

220

221 Fever (axillary temperature of $\geq 37.5^{\circ} \mathrm{C}$ ) and malariological indices varied with age (Fig. 2).

222 The risk of fever was at a maximum in children less than 1 year old and showed a gradual 223 decline with age (Fig. 2a). The prevalence of $P$. falciparum parasitaemia peaked in the 5-9 224 year age group (Fig. 2b), but median parasite densities were highest in the 1-4 year age 225 group (Fig. 2c). Blood stage parasites were not seen in five of the 21 gametocyte carriers 226 identified in 2009, in seven of 14 identified in 2010 nor in eight of 21 identified in 2011. In 227 all years the majority (67\%) of gametocyte carriers were under 10 years of age, although 228 gametocytes were seen in all age groups (Fig. 2d). The prevalence of gametocytes dropped 229 from 39.5\% (135 of 342) in P. falciparum positive slides before the opening of the clinic to $23014.7 \%$ (33 of 224) once it had opened $\left(\Sigma^{2}=22.6, \mathrm{p}=<0.05\right)$. Plasmodium malariae also 231 peaked in 5-9 year olds, but the numbers recorded were very small (Fig. 2e). Among people 232 attending the surveys reported bednet use was lowest among 10-19 year olds (Fig. 2f). 233 The reasons given for non-use included that the net was 'too hot'; that there were no 234 mosquitoes; that they were ill or that they just didn't like it.

236 In $2007,24.4 \%$ (11 of 45) of the malaria positive individuals were children less than five 237 years old whilst in 2011 only $8.9 \%$ (5 of 56) of the malaria positive individuals were 238 children less than five years old. 
239 Overall prevalence varied from one survey to the next with a marked increase in 240 prevalence in the 2009 survey (Fig. 3). More than $1,000 \mathrm{~mm}$ of rain were recorded in

241 Maxixe over the wet season of 2009 compared to the less than $400 \mathrm{~mm}$ recorded in 2007.

242 More rain in 2009 may have affected prevalence. Not only was there less rain in 2007 but

243 also it fell later (the peak rain falling in the first week of April -week 14) compared to other

244 years (which varied from week 49 to week 4). Indeed, the survey in 2007 took place during

245 the rains whilst the other surveys were undertaken at lags of seven (2008), 13 (2009), 17

246 (2010) and 18 (2011) weeks after the peak week of rain.

248 Risk Factors.

A multiple logistic regression model was fitted to the data from the 618 surveyed people

251 for which matching covariate data was available from the census. A significant relationship

252 was observed between being infected with malaria and year of survey, age group, roof

253 category, door category, number of people per household, water source category, washing

254 water category and whether or not the surveyed person slept under a bednet on the

255 previous night. Thus, after adjusting for other risk factors, people who lived in houses

256 having a roof made of thatch or other 'Green' material had an increased risk of having

257 parasites than those who lived in houses with a roof of corrugated iron or other man-made

258 material. The number of people living in the house was also a risk as was age.

259 Using a backwards, stepwise model selection approach, the final fitted model included year,

260 age group, number of people in the house and roof category (Table 3). A generalised

261 additive model (GAM), i.e. a logistic regression model with a smooth term for spatial

262 location, was fitted to the individual-level data to determine whether there was any spatial 
263 pattern in malaria prevalence after accounting for observed risk factors (see the 264 supplementary information). The fitted GAM indicated that there was an area of lower risk 265 in the southeast of the study region, and an area of higher risk in the north and west of the 266 study area (Fig. 4).

Incidence data

272

273

In the 28 months (March 2009 - May 2011) that the clinic was operational there were 4929 visits to the Clinic, with 4308 (87\%) of attendees residing in Linga Linga. Hence, despite its isolation $621(13 \%)$ of the people attending were non-residents. Residents and visitors were analysed separately.

277

Among the residents, 31.2\% (1343/4308) were clinically diagnosed with malaria and 868 279 (65\%) of these were tested by blood slide and/or RDT, resulting in 543 (63\%) who tested positive for P. falciparum.

281

282 Fever and malariological indices among residents attending the clinic varied with age (Fig.

283 5). The risk of fever was at a maximum in 1-4 year old children. As in the prevalence 284 surveys it declined with age but in this case more slowly (Fig. 5a). Significantly more of the 285 attendees with fever were malaria positive than those without fever $\left(\chi^{2}\right.$ for diagnosis $=$ $286131.9 \mathrm{p}<0.0001$, positivity among those tested $\left.\chi^{2}=12.6 \mathrm{p}=0.0004\right)$. Of the 586 people 
287 who had, or reported having had, a fever when attending the clinic, 348 (59\%) were 288 clinically diagnosed with malaria and of the 209 tested (either microscopically or with 289 RDT), $167(80.4 \%)$ were positive. From the 2423 people recorded attending without a 290 history of fever, 995 (36.5\%) were clinically diagnosed with malaria out of which, 659 of 291 these patients were tested and 283 (42.9\%) were positive.

292

293 Overall peak diagnosis and peak positivity occurred in the 5-9 year age group (Fig. 5b \& 294 5c). Thus the accuracy of the diagnosis was greatest in this age group. As in the prevalence 295 surveys reported bednet use among residents attending the clinic was lowest among 10-19 296 year olds (Fig. 5e). People using a net the night before reporting ill were, however, as 297 likely to have malaria as those who did not - of the 720 people who reported using a net 298 that were diagnosed and tested for malaria, 450 (63\%) were positive, whilst of the 148 299 tested who did not use a net, 93 (63\%) were positive for malaria.

300

301 In the $20-39$ and the over 40 years age groups more females than males were diagnosed 302 or tested for malaria, but the majority of these tests were negative (Fig 6).

303

304 A similar proportion (34\%; 213/621) of non-residents were clinically diagnosed with 305 malaria. Among these, 142 (67\%) were tested by microscopy and/or RDT and 79 (56\%) 306 were positive. Among non-residents, 84 of the diagnosed cases came from urban areas 307 (where transmission is low or absent) and 117 (58\%) came from nearby rural areas 308 (where autochthonous transmission is likely to occur). There was, however, no significant 
309 difference in the likelihood of urban and rural non-residents having a confirmed case of

310 malaria (two tailed Fishers exact test $\mathrm{p}=0.217$ ).

311

312 Fever and malariological indices among visitors attending the clinic also varied with age in

313 much the same way that they did among residents (Fig. 7 a-d).

314

315 The proportion of under nine year old resident attendees diagnosed with malaria

316 decreased significantly from 48\% in 2009, to 35\% in 2010 and $25 \%$ in 2011 (for under 1

317 year olds $\chi^{2}=10.5 \mathrm{p}=0.005$; for 1 to 4 year olds $\chi^{2}=24.4 \mathrm{p}=>0.000$, for $5-9$ year olds $\chi^{2}=$

$3185.92 \mathrm{p}=0.52$ ). At the same time there was a shift in the peak age of cases from 1-4 year

319 olds to 5-9 year olds (Fig. 8).

320 In under nine year olds the incidence of malaria was seasonal and followed the rainfall (Fig.

321 9). The highest correlation between cases and rainfall occurred with a lag of nine weeks

322 (Spearman correlation co-efficient between incidence and weekly rainfall $=0.34 \mathrm{p}=$

$3230.0002)$.

324

325 There was no significant clustering of cases attending the clinic, although by mapping the

326 number of visits per household and weighting these values by number of people in the

327 household (obtained from the census data), there was evidence that those living away from

328 the clinic were less likely to attend (Spearman correlation co-efficient between distance to

329 clinic and number of visits per person per household $=-0.1492, p=0.0031$ ) (Fig. 10). 330 


\section{Discussion}

333

334 Patterns of malariological indices observed during the prevalence surveys were similar to

335 those reported from the Kilombero valley from 1989-1991 (Smith et al., 1993), but

336 transmission was considerably lower. Peak prevalence of P. falciparum was, however,

337 observed in the 5-9 year age group rather than the 1-4 year age group recorded in the

338 Kilombero. The prevalence of P. malariae also peaked in 5-9 year olds. Despite peaking in

339 the 1-4 year age group the median P. falciparum density was half that described from the

340 Kilombero, whilst clinical malaria episodes occurred in all ages of hosts in Linga Linga. This

341 suggests that the level of clinical immunity never reaches the levels achieved by

342 adolescents in holoendemic areas. Nevertheless, despite the lower transmission there was

343 considerable mixing of parasites since the frequency of the Pfcrt

344 CVMNK wild type gene in P. falciparum from Linga Linga increased from $44 \%$ to $66 \%$

345 within a single year (Thomsen et al., 2013). Smith et al. (1993) concluded in their paper, on

346 transmission in the Kilombero, that "The effects of interventions such as impregnated

347 bednets on parasite prevalence or density are likely to be minimal.' In other areas where

348 there is moderately intense seasonal transmission, such as The Gambia, there is highly

349 seasonal malaria morbidity but also much less seasonality in parasite prevalence

350 (Greenwood et al., 1987, Lindsay et al., 1991). Thus, even at the intensity of transmission

351 observed in Linga Linga, it is possible that effects on prevalence due to the widespread use

352 of LLIN's are overridden by other, periodic and chaotic effects, as suggested by

353 Kwiatkowski and Novak (1991). 
355 In general we have no reason to suppose that isolation causes the clinical epidemiology of

356 malaria in Linga Linga to differ from that on continental Africa. Malaria was the most

357 common diagnosis for children under ten years of age attending the clinic. Fever peaked in

358 the 1-4 year olds, but the proportion of attendees diagnosed with malaria was greatest in

359 the 5-9 year olds. Diagnosis was also more accurate in children under ten years of age than

360 in older age groups, most of whom were women. It is likely that these were mothers or

361 carers of sick children who also asked to be tested for malaria when they brought their sick

362 child to the clinic.

363

364 Obtaining good incidence data is often difficult because of the multiple avenues by which

365 people get treatment for perceived malaria. Clinics such as the one operating in Linga

366 Linga, in which patients were well received and treated with courtesy, in which there are

367 no stock-outs, and which might be the only source of anti-malarial medicine for miles

368 around, are both appreciated and useful.

370 Together the interventions appeared to have a major impact on incidence and morbidity.

371 Among children below ten years of age the proportion diagnosed with malaria decreased

372 by almost a half during the time that the clinic was open. At the same time there was a shift

373 in the peak age of incidence towards older age groups. Although not statistically significant,

374 the possible peak shift from 1-4 to 5-9 year olds in prevalence rates in sequential

375 prevalence surveys may also be due to the interventions (Smith et al., 2001, Ishengoma et

376 al, 2013). Although these changes may have been partly due to the use of nets, these had

377 been available for more than a year prior to the opening of the clinic and it may be that the

378 clinic itself was having an impact. Treatment with ACT significantly reduces infectiousness 
379 of individual patients with uncomplicated falciparum malaria compared to previous first

380 line treatments. Rapid treatment of cases before gametocytaemia is well developed may

381 enhance the impact of ACT on transmission (Okell et al., 2011). The drop in the prevalence

382 of gametocytes from surveys undertaken before the opening of the clinic to that observed

383 (by the same two microscopists) once it was in operation may, therefore, have been due to

384 the more widespread use of ACT's and this may have reduced transmission.

385

386 Reducing risk factors may also reduce transmission. We were able to identify a variety of

387 risk factors, some of which can perhaps be reduced. For example, living in a house with a

388 thatched roof was associated with an enhanced malaria risk. Anopheles funestus may be

389 more likely to rest inside houses that have thatch, rather than iron, roofs. Should the

390 mosquito, due to the lack of suitable oviposition sites, have an extended gonotrophic cycle,

391 as postulated by Charlwood et al., (2013), then it may feed where it rests (rather than

392 merely rests where it feeds). Hence occupants of thatched roofed houses may be at greater

393 risk of transmission than those in iron roofed ones (Kirby et al., 2008, Mmbando et al.,

394 2011, Tami et al., 2012). Although it produces a shift, as e.e. cummings would say, from a

395 'world of born' to a 'world of made', the replacement of thatch with tin roofs would 396 probably reduce transmission in Linga Linga and similar areas.

397

398 The number of inhabitants in a house and their age were also risk factors. Greater numbers 399 of mosquito are attracted to houses as the number of occupants increase (Charlwood et al., 400 2013). Should infected mosquitoes be more likely to take interrupted feeds on different 401 hosts (Anderson et al., 2000) then, even if the numbers of mosquito per inhabitant remain 
402 the same, the risk of transmission will be greater. Having individual bedrooms would make

403 it more difficult for the mosquito to take such interrupted feeds on multiple hosts.

404

405 In Linga Linga the risk of being parasite positive was higher towards the northern end of

406 the peninsular. The northern end of the peninsula is more sheltered and less exposed to

407 wind and has a higher exposure to anophelines (Charlwood et al., 2013) than the southern

408 end of the peninsula. The use of LLINs should particularly be encouraged (and monitored)

409 among the inhabitants of the northern end of the peninsular. Incidence was seasonal, with

410 a peak of cases nine weeks after peak rainfall. This should enable health authorities to plan

411 drug supplies to ensure that the clinic has an adequate supply of drugs for such times.

412

413 The increasing number of people who did not have an associated house number in the

414 years following the census indicates that, despite its isolation, there was a considerable

415 movement of people into, and perhaps out of, Linga Linga. Among non-residents, 58\% of

416 attendees at the clinic came from areas where active transmission was likely to have

417 occurred and so they may have been importing malaria into the area, whilst $42 \%$ came

418 from urban areas where transmission is low or absent and they may have acquired their

419 malaria on the peninsula. Thus, not only do areas like Linga Linga pose a threat to non-

420 immunes (from the cities) but importation of malaria is also a continuing possibility.

421 Importation of malaria will pose problems for future elimination projects in isolated areas

422 like Linga Linga.

423 
424 Should people arrive without nets and should there not be a system that enables them to

425 obtain them, then the risk of transmission will be maintained. Visitors, including those

426 from urban areas, attending the clinic were, however, as likely as residents to have slept

427 under a bednet before attending. Since people rarely travel with their own net this implies

428 that, despite the low numbers of nets distributed, there were sufficient nets available for 429 guests to be provided with one.

430

431 Elsewhere malaria appears to be close to elimination in a number of islands in which ACTs 432 and bednets, (Battarai et al., 2007) and/or indoor residual spraying of insecticides 433 (Teklehaimanot et al., 2010) combined with active surveillance of cases (Lucas, 2010, Lum 434 et al., 2007) have been used, although the caveat to this is that resurgence is always 435 possible (Hadji et al., 2013). Resistance to pyrethroids in An. funestus is widespread (being 436 detected from South Africa to Mozambique and Malawi). The mosquito from the village of 437 Furvela, 8km from Linga Linga, was resistant to the insecticide when tested in 2009 438 (Charlwood, J.D. and Kampango, A., unpublished data). It is, therefore, likely that the 439 mosquito in Linga Linga was also resistant to the insecticide used on the nets in the present 440 study. Given the endophilic nature of An. funestus, indoor residual spraying (IRS) has been 441 successful against this vector in the past. IRS is, however, expensive ( $30 \$$ per house) and 442 time limited.

443

444 Even with an effective insecticide resistance will eventually develop and reliance on 445 conventional control measures (including LLIN's, ACT's and IRS) may therefore eventually 446 lead to rebounds in transmission as selection against these measures (in the mosquito or 
447 the parasite) starts becoming effective (Hadji et al., 2013). Hence, despite a proven

448 effectiveness of IRS, and because of its cost, additional alternative control measures are

449 likely to be needed, even to maintain present gains. Such measures should be simple, easy

450 to apply on a do-it-yourself basis, and should be long lasting in their effect and not based on

451 insecticides. In addition, or as an alternative, to replacing a thatch roof with one of tin,

452 applying old mosquito netting over the openings where mosquitoes enter houses would be

453 useful (Kampango et al., 2013). This technique does not dramatically reduce airflow or

454 illumination but reduces mosquito entry. It can be done on a DIY basis and once in place

455 does not need the householder to do anything to maintain protection.

456

457 We have also previously shown that exposure to vectors in Linga Linga is greatest close to 458 the temporary pond, some $800 \mathrm{~m}$ from the clinic. Larviciding this pond and the limited 459 number of known breeding sites at the start of the rainy season would also be an obvious 460 thing to do (Keiser et al., 2005). Preventively treating children less than nine years of age, 461 the most at risk group, at this time may also be useful (Aponte et al., 2009).

\section{Conclusions}

Even in areas like Linga Linga with a low vector population transmission can be relatively

465 intense. Surveys of the sort undertaken can provide information on the spatial distribution 466 of malaria, which may help in the optimum location of clinics. Although prevalence varied

467 greatly from one year to the next there was a shift in prevalence towards older age groups 468 over time. Incidence, although measured imperfectly, clearly dropped in the most affected 
469 age groups following the introduction of both LLINs and a clinic dispensing ACT's. The

470 replacement of grass roofs for corrugated iron ones would reduce malaria risk

471

472

473

474

475

476

477

478

479

480

481

482

483

484

485

486

487

488

489

490

491

492

493

494

495

496

497

498

\section{Acknowledgements}

We thank the project staff, especially Sr Quipisso and his assistant Judith Joaquim for running the clinic. Thanks too to the District Health Authority of Morrumbene for supplying the medicines used at the clinic and to Vestergaard-Frandsen for supplying the nets. We thank Olivier Briët, Virgilio de Rosiario, Bruno de Souza and Louise Kelly-Hope for comments on the study and the referees whose perceptive comments helped improve the manuscript. We thank Dominique and Luke Shoham for copy editing the manuscript.

We also thank the people of Linga Linga who participated in the study. Danish Centre for Health Research \& Development, University of Copenhagen, Denmark, funded the study.

\section{References}

Anderson, R.A., B. Knols, J. Koella. 2000. Plasmodium falciparum sporozoites increase feeding-associated mortality of their mosquito hosts, Anopheles gambiae s.l. Parasitology 120, 329-333.

Aponte, J.J., D. Schellenberg, A. Egan, A. Breckenridge, I. Carneiro, J. Critchley, I. Danquah, A. Dodoo, R. Kobbe, B. Lell, J. May, Z. Premji, S. Sanz, E. Sevene, R. Soulaymani-Becheikh, P. Winstanley, S. Adjei, S. Anemana, D. Chandramohan, S. Issifou, F. Mockenhaupt, S. Owusu-Agyei, B. Greenwood, M.P. Grobusch, P.G. Kremsner, E. Macete, H. Mshinda, R.D. Newman, L. Slutsker, M. Tanner, P. Alonso and C. Menendez. 2009. Efficacy and safety of intermittent preventive treatment with sulfadoxinepyrimethamine for malaria in African infants: a pooled analysis of six randomised, placebo-controlled trials. Lancet 374, 1533-1542. 

Komatsu, E. Korenromp and M. Hosseini. 2011. Reductions in malaria and anaemia case and death burden at hospitals following scale-up of malaria control in Zanzibar, 19992008. Malar. J. 10, 46.

504

Bhattarai, A., Ali, A. S., Kachur, S. P., Mårtensson, A., Abbas, A. K., Khatib, R., ... Björkman, A. (2007). Impact of Artemisinin-Based Combination Therapy and Insecticide-Treated Nets on Malaria Burden in Zanzibar. PLoS Medicine, 4(11), e309. doi:10.1371/journal.pmed.0040309

Bruce-Chwatt, L.J. 1985. Essential Malariology, William Heinmann Medical Books $\left(2^{\text {nd }}\right.$ edn).

Charlwood, J.D., N. Cuamba, E.V.E. Tomás and O.J. Briët. 2013. Living on the edge: a longitudinal study of Anopheles funestus in an isolated area of Mozambique. Malar. J. 12, 208.

516

Greenwood, B.M., Bradley, A.K., Greenwood, A.M., Byass, P., Jammeh, K., Marsh, K., among children in a rural area of The Gambia, West Africa. Trans. R. Soc. Trop. Med. Hyg. 81, 478-486.

Hagmann, R., J.D. Charlwood, V. Gil, V. do Rosario and T. Smith. 2003. Malaria and its possible control on the island of Príncipe. Malar. J. 2,9.

Haji, K. A., Khatib, B. O., Smith, S., Ali, A. S., Devine, G. J., Coetzee, M., \& Majambere, S. (2013). Challenges for malaria elimination in Zanzibar: pyrethroid resistance in malaria vectors and poor performance of long-lasting insecticide nets. Parasites \& Vectors, 6, 82. doi:10.1186/1756-3305-6-82

Ishengoma, D.A., B.P. Mmbando, M.D. Segeja, M. Alifrangis, M.M. Lemnge and I.C. Bygbjerg. 2013. Declining burden of malaria over two decades in a rural community of Muheza District, north-eastern Tanzania. Malar. J. 12, 338.

Kampango, A., M. Bragança, B. de Souza and J.D. Charlwood. 2013. Netting barriers to prevent mosquito entry into houses in southern Mozambique: a pilot study. Malar. J. 12,99 .

Keiser, J., B.H. Singer and J. Utzinger. 2005. Reducing the burden of malaria in different eco-epidemiological settings with environmental management: a systematic review. Lancet Infect. Dis., 5, 695-708.

Khatib, R. A., Skarbinski, J., Njau, J. D., Goodman, C. A., Elling, B. F., Kahigwa, E., ... Kachur, S. P. 2012. Routine delivery of artemisinin-based combination treatment at fixed health 
544 facilities reduces malaria prevalence in Tanzania: an observational study. 11, 140. doi:10.1186/1475-2875-11-140

546

Kirby, M.J., C. Green, P.M. Milligan, C. Sismanidis, M. Jasseh, D.J. Conway and S.W. Lindsay. 2008. Risk factors for house-entry by malaria vectors in a rural town and satellite villages in The Gambia. Malar. J. 7, 2.

550

551

552

553

554

555

556

557

558

559

Kwiatkowski, D. and Novak, M. 1991. Periodic and chaotic host-parasite interactions in human malaria. Proc. Natl. Acad. Sci. USA. 88, 5111-5113.

Lindsay, S.W., Wilkins, H.A., Zieler, H.a., Daly, R.J., Petreaca, V. and Byass, P. 1991. Ability of Anopheles gambiae mosquitoes to transmit malaria during the dry and wet seasons in an area of irrigated rice cultivation in The Gambia. Trans. R. Soc. Trop. Med. Hyg. 94, 313-324.

Lucas, A.M. 2010. Malaria eradication and educational attainment: Evidence from Paraguay and Sri Lanka. Am. Econ. J.: Applied Economics 2, 46-71.

Lum, J.K., A. Kaneko, G. Taleo, M. Amos and D.M. Reiff. 2007. Genetic diversity and gene flow of humans, Plasmodium falciparum and Anopheles farauti s. s. of Vanuatu: Inferred malaria dispersal and implications for malaria control. Acta Trop. 103, 102-107.

Mmbando, B. P., Kamugisha, M. L., Lusingu, J. P., Francis, F., Ishengoma, D. S., Theander, T. G., ... Scheike, T. H. (2011). Spatial variation and socio-economic determinants of Plasmodium falciparum infection in northeastern Tanzania. Malar. J. 10, 145. doi:10.1186/1475-2875-10-145

Okell, L.C., C.J. Drakeley, A.C. Ghani, T. Teun Bousema and C. J. Sutherland. 2008. Reduction of transmission from malaria patients by artemisinin combination therapies: a pooled analysis of six randomized trials. Malar. J. 7, 125.

Pinto, J., M.J. Donnelly, C.A. Sousa, J. Malta-Vacas, V. Gil, C. Ferreira, V. Petrarca, V. E. do Rosario and J.D. Charlwood. 2003. An island within an island: Genetic differentiation of Anopheles gambiae in São Tomé, West Africa, and its relevance to malaria vector control. Heredity 91, 407-414.

R Core Team. 2013. R: A Language and Environment for Statistical Computing. Vienna: $\mathrm{R}$ Foundation for Statistical Computing.

Smith, T., Charlwood, J.D., Kihonda, J., Mwanyakusye, S., Billingsley, P., Meuwissen, J., Takken, W., Teuscher, T. and Tanner, M. 1993. Absence of seasonal variation in malaria parasitaemia in an area of intense seasonal transmission. Acta Tropica 54, 55-72.

Smith, T., J.L. Hii, I. Müller, M. Booth, N. Gibson, A. Narara and M.P. Alpers. 2001. Associations of peak shifts in age--prevalence for human malarias with bednet coverage. Trans. R. Soc. Trop. Med. Hyg. 95, 1-6. 
590

591

592

593

594

595

596

597

598

599

600

601

602

603

604

605

606

607

608

609

610

611

612

613

614

615

616

617

618
Sudomo, M.,Y. Arianti, I. Wahid, D. Safruddin, E.M. Pedersen and J.D. Charlwood. 2010. Towards Eradication: Three Years after the Tsunami of 2004, Has malaria transmission been eliminated from the island of Simeulue? Trans. R. Soc. Trop. Med. Hyg. 104, 777781.

Tami, E.A., M. Coleman, A.P. Abilio and I. Kleinschmidt. 2012. High prevalence of malaria in Zambezia, Mozambique: the protective effect of IRS versus increased risk due to pigkeeping and house construction. PLoS One, 7:e31409. Doi: 10.1371/journal.pone.0031409.Epub2012 Feb 20

Teklehaimanot, H.D., A. Teklehaimanot, A. Kiszewski, H.S. Rampao and J.D. Sachs. 2010. Malaria in São Tomé and Príncipe: On the brink of elimination after three years of effective antimalarial measures. Am. J. Trop. Med. Hyg. 80, 133 - 140.

Thomsen, T.T., L.B. Madsen, H.H. Hansson, E.V.E. Tomás, J.D. Charlwood, I.C. Bygbjerg and M. Alifrangis. 2013. Rapid selection of Plasmodium falciparum chloroquine resistance transporter gene and multidrug resistance gene-1 haplotypes associated with past chloroquine and present artemether-lumefantrine use in Inhambane District, southern Mozambique. Am. J. Trop. Med. Hyg. 883, 536-541.

World Health Organization. http://www.afro.who.int/en/mozambique/countryprogrammes/disease-prevention-and-control/malaria.html (accessed 7/11/2014). www.theodora.com (accessed 7/11/2014).

www.unicef.org/mozambique/child_survival_2933.html 
1

Map of Linga Linga showing the distribution of houses recorded in the census of 2007 according to roof type. 


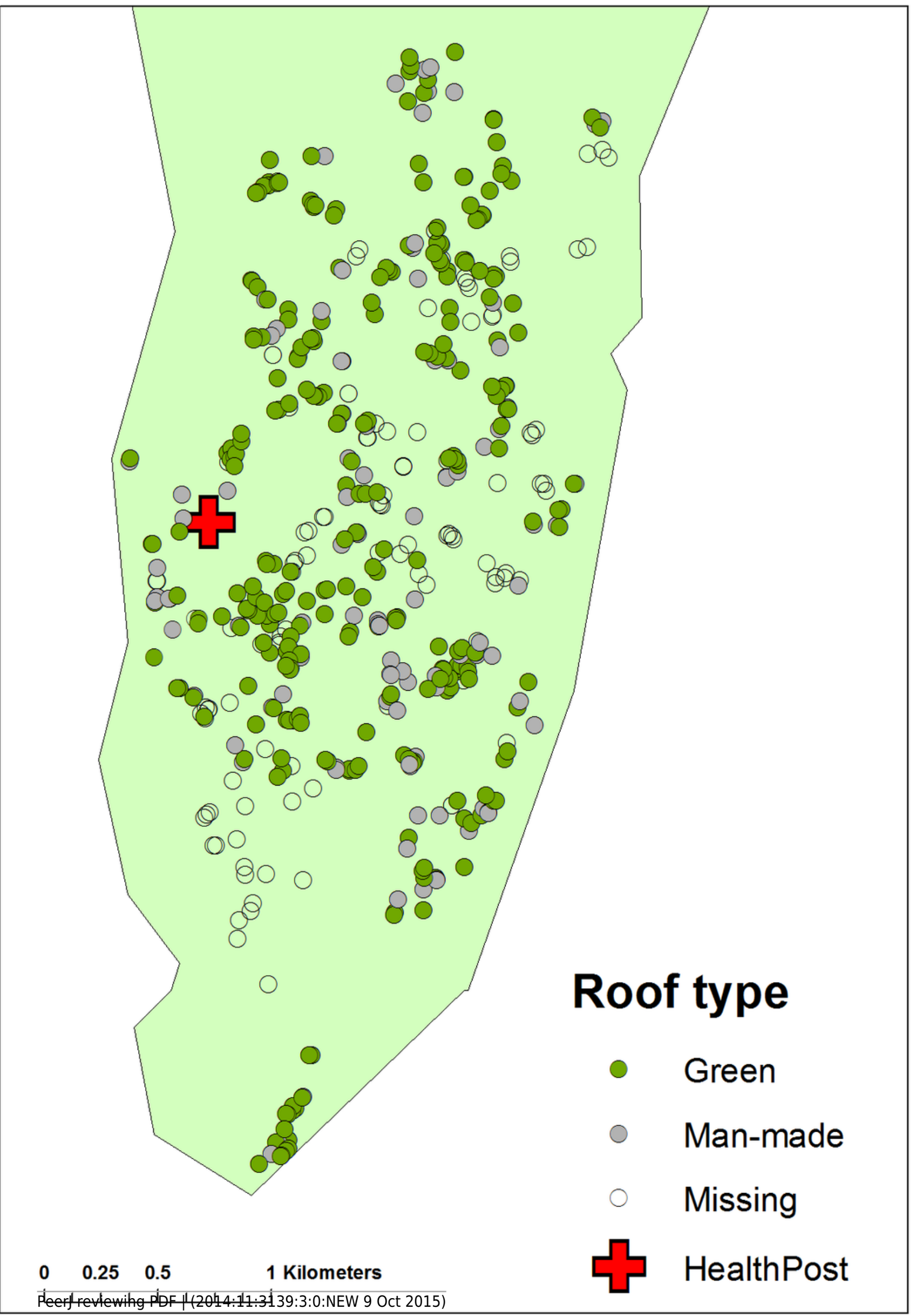




\section{Table $\mathbf{1}$ (on next page)}

Number of people recorded in the 2007 census, number of slides taken during prevalence surveys and attendance at the clinic (residents and visitors) by age group, Linga Linga, Mozambique 
1

\begin{tabular}{|c|c|c|c|c|c|c|c|c|}
\hline \multirow[b]{2}{*}{$\begin{array}{l}\text { Age in } \\
\text { years }\end{array}$} & \multirow[b]{2}{*}{$\begin{array}{c}\text { Census } \\
2007\end{array}$} & \multirow{2}{*}{$\begin{array}{c}\text { Prevalence } \\
\text { Number of } \\
\text { slides }\end{array}$} & \multirow[b]{2}{*}{$\begin{array}{c}\text { Resident } \\
\text { attendance }\end{array}$} & \multirow[b]{2}{*}{$\begin{array}{c}\text { Number } \\
\text { diagnosed }\end{array}$} & \multicolumn{2}{|c|}{ Incidence } & \multirow[b]{2}{*}{$\begin{array}{c}\text { Number } \\
\text { diagnosed }\end{array}$} & \multirow[b]{2}{*}{$\%$ positive } \\
\hline & & & & & $\%$ positive & $\begin{array}{c}\text { Visitor } \\
\text { attendance }\end{array}$ & & \\
\hline$<1$ & 43 & 49 & 342 & 52 & 74 & 25 & 5 & 100 \\
\hline $1-4$ & 66 & 182 & 968 & 223 & 83 & 93 & 31 & 80 \\
\hline $5-9$ & 119 & 442 & 588 & 159 & 80 & 28 & 28 & 100 \\
\hline $10-19$ & 227 & 457 & 466 & 108 & 70 & 65 & 65 & 75 \\
\hline $20-39$ & 248 & 182 & 2435 & 484 & 54 & 237 & 237 & 68 \\
\hline$>40$ & 266 & 386 & 2051 & 317 & 48 & 170 & 170 & 53 \\
\hline
\end{tabular}

2 


\section{Table 2 (on next page)}

Summary of data sets from the prevalence surveys 2007-2011, Linga Linga peninsular, Mozambique. 


\begin{tabular}{|c|c|c|c|c|c|c|c|}
\hline \multirow[b]{2}{*}{ Year } & \multicolumn{4}{|c|}{ Raw data } & \multicolumn{3}{|c|}{ Matched data } \\
\hline & $\begin{array}{l}\text { Number of } \\
\text { individuals }\end{array}$ & $\begin{array}{l}\% \text { with } \\
\text { house } \\
\text { number }\end{array}$ & $\begin{array}{l}\text { Number } \\
\text { of } \\
\text { Houses }\end{array}$ & \% Positive & $\begin{array}{l}\text { Number of } \\
\text { individuals }\end{array}$ & $\begin{array}{l}\text { Number of } \\
\text { Houses }\end{array}$ & $\%$ Positive \\
\hline 2007 & 411 & $91 \%$ & 229 & $16 \%$ & 308 & 179 & $15 \%$ \\
\hline 2008 & 345 & $59 \%$ & 158 & $34 \%$ & 191 & 136 & $24 \%$ \\
\hline 2009 & 435 & $68 \%$ & 183 & $65 \%$ & 285 & 160 & $67 \%$ \\
\hline 2010 & 398 & $56 \%$ & 137 & $29 \%$ & 220 & 127 & $27 \%$ \\
\hline 2011 & 282 & $48 \%$ & 103 & $44 \%$ & 131 & 99 & $44 \%$ \\
\hline $\begin{array}{r}\text { Total } \\
1 \\
2\end{array}$ & 1871 & $66 \%$ & 230 & $38 \%$ & 1135 & 332 & $35 \%$ \\
\hline
\end{tabular}




\section{Figure 2 (on next page)}

Age dependence and malariological indices, Linga Linga, Mozambique

Prevalence surveys - a) fever, b) prevalence $P$. falciparum, c) median $P$. falciparum density, d) prevalence of $P$. falciparum gametocytes, e) $P$. malariae, f) used net 

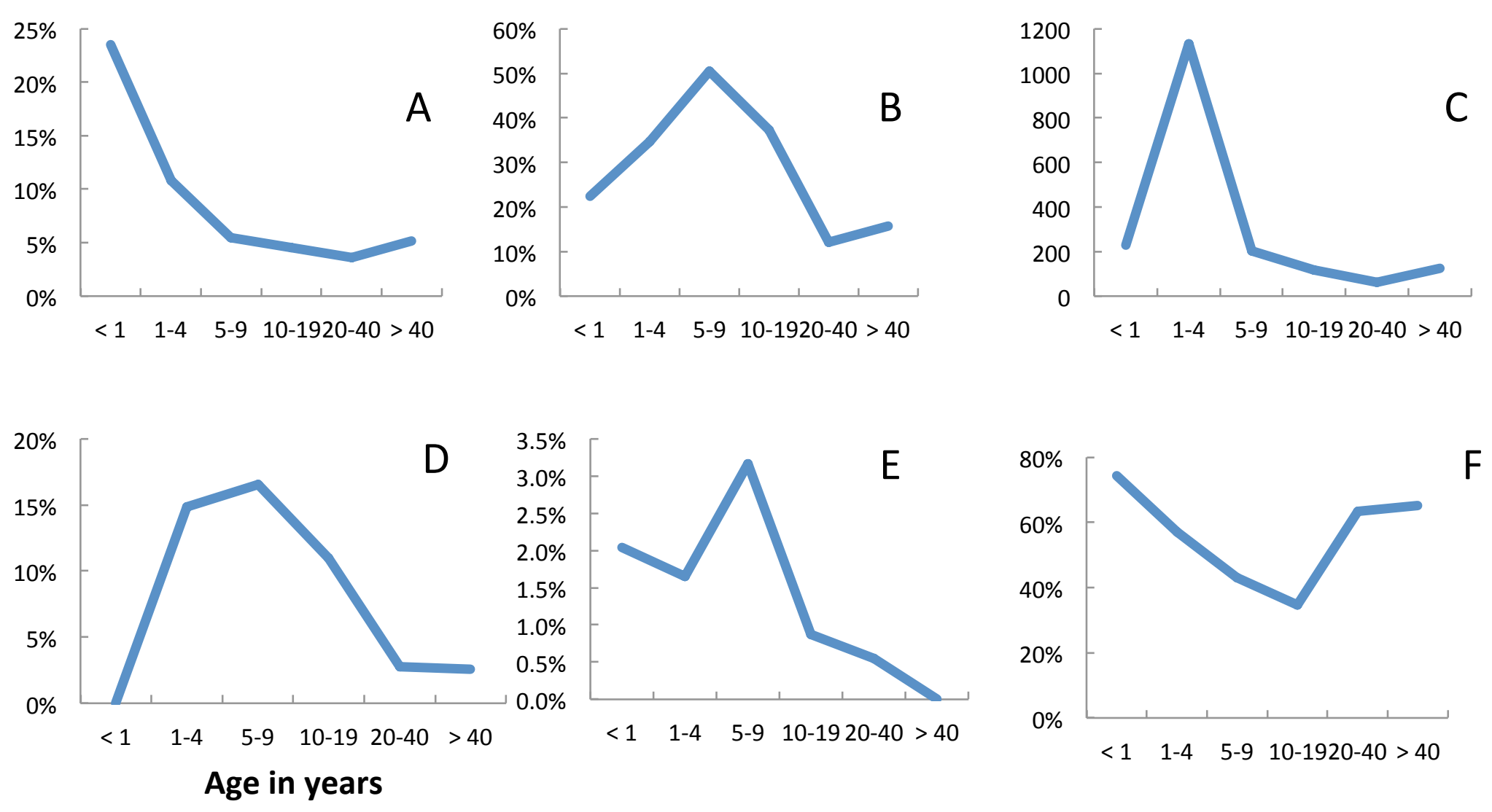
Figure 3 (on next page)

Prevalence and rainfall, Linga Linga, Mozambique

Annual prevalence by age group and rainfall (measured in Maxixe), Linga Linga, Mozambique 


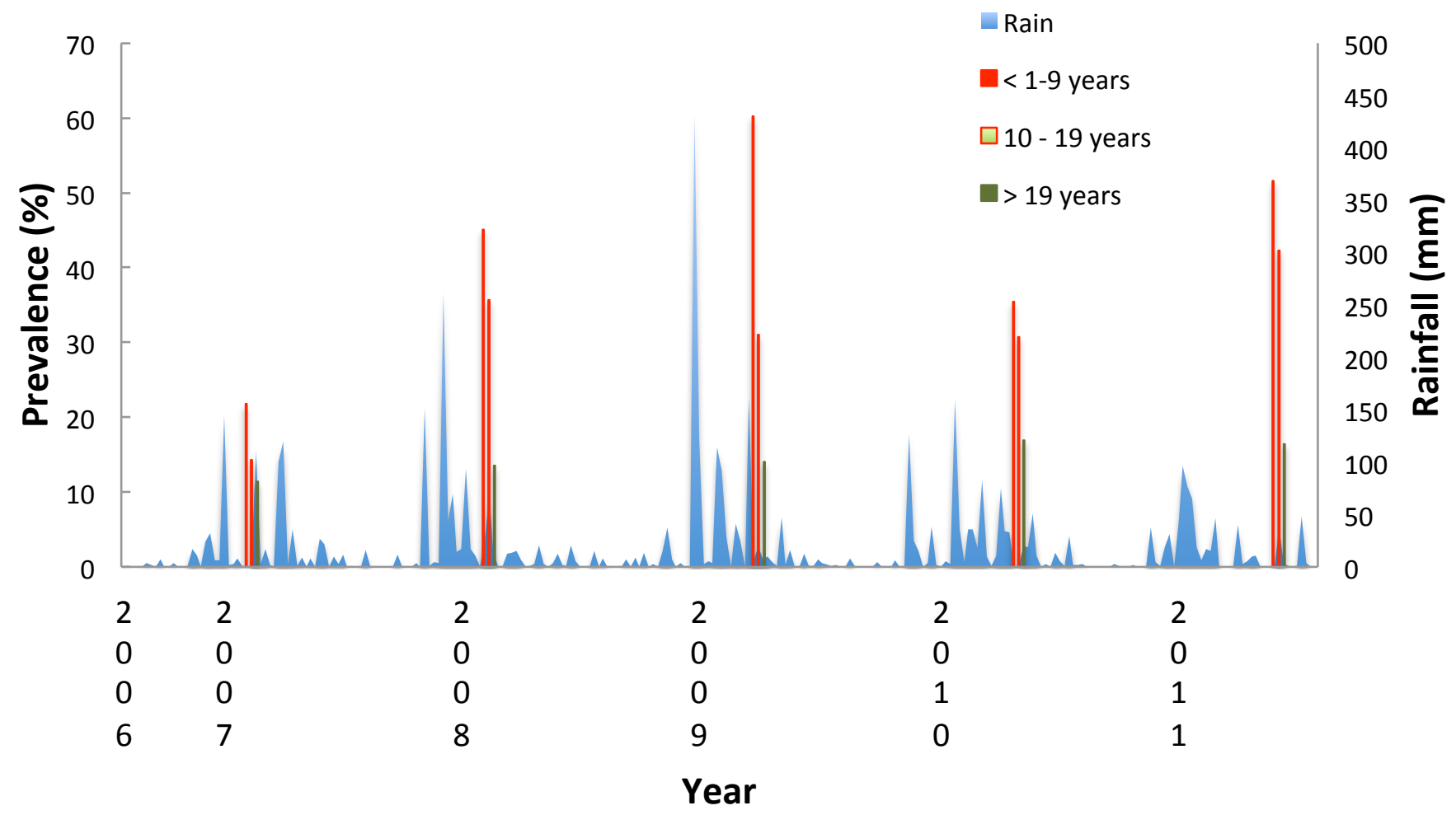




\section{Table 3(on next page)}

Individual and household characteristics by malaria status

Summaries of individual and household characteristics by malaria status and adjusted oddratios obtained from fitting a multiple logistic regression model to the data from malaria prevalence surveys 2007-2011, Linga Linga peninsular, Mozambique 
$\underline{1}$

\begin{tabular}{|c|c|c|c|c|c|c|c|c|}
\hline & \multicolumn{4}{|c|}{ Malaria test result } & \multirow{3}{*}{ Total } & \multirow{3}{*}{$\mathbf{O R}$} & \multirow{3}{*}{$95 \%$ CI } & \multirow{3}{*}{ p-value } \\
\hline & \multicolumn{2}{|c|}{ Positive } & \multicolumn{2}{|c|}{ Negative } & & & & \\
\hline & $\mathbf{N}$ & $(\%)$ & $\mathbf{N}$ & $(\%)$ & & & & \\
\hline \multicolumn{9}{|l|}{ Year } \\
\hline 2007 & 45 & $(15 \%)$ & 263 & $(85 \%)$ & 308 & & & \\
\hline 2008 & 46 & $(24 \%)$ & 145 & $(76 \%)$ & 191 & 1.91 & $1.10-3.29$ & 0.0206 \\
\hline 2009 & 190 & $(67 \%)$ & 94 & $(33 \%)$ & 284 & 11.4 & 7.29-18.07 & $<0.0001$ \\
\hline 2010 & 60 & $(27 \%)$ & 160 & $(73 \%)$ & 220 & 3.05 & $1.88-5.00$ & $<0.0001$ \\
\hline 2011 & 57 & $(44 \%)$ & 74 & $(56 \%)$ & 131 & 4.97 & $2.88-8.63$ & $<0.0001$ \\
\hline \multicolumn{9}{|l|}{ Sex } \\
\hline Female & 226 & $(32 \%)$ & 472 & $(68 \%)$ & 698 & & & \\
\hline Male & 167 & $(40 \%)$ & 255 & $(60 \%)$ & 422 & & & \\
\hline Missing & 5 & $(36 \%)$ & 9 & $(64 \%)$ & 14 & & & \\
\hline \multicolumn{9}{|l|}{ Age group } \\
\hline$<1$ & 12 & $(27 \%)$ & 32 & $(73 \%)$ & 44 & & & \\
\hline $1-4$ & 39 & $(44 \%)$ & 49 & $(56 \%)$ & 88 & 2.71 & $1.04-7.50$ & 0.0472 \\
\hline $5-9$ & 108 & $(45 \%)$ & 133 & $(55 \%)$ & 241 & 3.31 & $1.40-8.44$ & 0.0086 \\
\hline $10-15$ & 106 & $(39 \%)$ & 167 & $(61 \%)$ & 273 & 2.22 & $0.94-5.64$ & 0.0783 \\
\hline $16-25$ & 21 & $(21 \%)$ & 78 & $(79 \%)$ & 99 & 0.76 & $0.28-2.14$ & 0.5879 \\
\hline$>25$ & 83 & $(27 \%)$ & 223 & $(73 \%)$ & 306 & 1.18 & $(0.503 .00)$ & 0.7119 \\
\hline$N A$ & 29 & $(35 \%)$ & 54 & $(65 \%)$ & 83 & & & \\
\hline \multicolumn{9}{|l|}{ Used net } \\
\hline No & 124 & $(30 \%)$ & 289 & $(70 \%)$ & 413 & & & \\
\hline Yes & 143 & $(38 \%)$ & 229 & $(62 \%)$ & 372 & & & \\
\hline$N A$ & 131 & $(38 \%)$ & 218 & $(62 \%)$ & 349 & & & \\
\hline \multicolumn{9}{|l|}{$\mathrm{N}^{0}$ people } \\
\hline 1 & 46 & $(26 \%)$ & 134 & $(74 \%)$ & 180 & & & \\
\hline 2 & 137 & $(37 \%)$ & 231 & $(63 \%)$ & 368 & 1.43 & $0.86-2.39$ & 0.1744 \\
\hline 3 & 120 & $(43 \%)$ & 160 & $(57 \%)$ & 280 & 1.85 & $1.09-3.17$ & 0.0236 \\
\hline$>3$ & 95 & $(31 \%)$ & 211 & $(69 \%)$ & 306 & 0.93 & $(0.551 .61)$ & 0.7987 \\
\hline
\end{tabular}

$\mathrm{N}^{\circ}$ bedrooms

$\begin{array}{llllll}1 & 314 & (34 \%) & 600 & (66 \%) & 914 \\ 2 & 70 & (38 \%) & 113 & (62 \%) & 183 \\ 3 & 14 & (38 \%) & 23 & (62 \%) & 37\end{array}$

Own animals

$\begin{array}{rllllllll}\text { Yes } & 248 & (35 \%) & 468 & (65 \%) & 716 & & & \\ \text { No } & 150 & (36 \%) & 268 & (64 \%) & 418 & & & \\ \text { Wall category } & & & & & & & & \\ \text { Other } & 53 & (39 \%) & 83 & (61 \%) & 136 & & & \\ \text { 'Green' } & 331 & (35 \%) & 621 & (65 \%) & 952 & 0.52 & 0.289-0.898 & 0.0115 \\ \boldsymbol{N A} & 14 & (30 \%) & 32 & (70 \%) & 46 & & & \end{array}$

\section{Roof category}




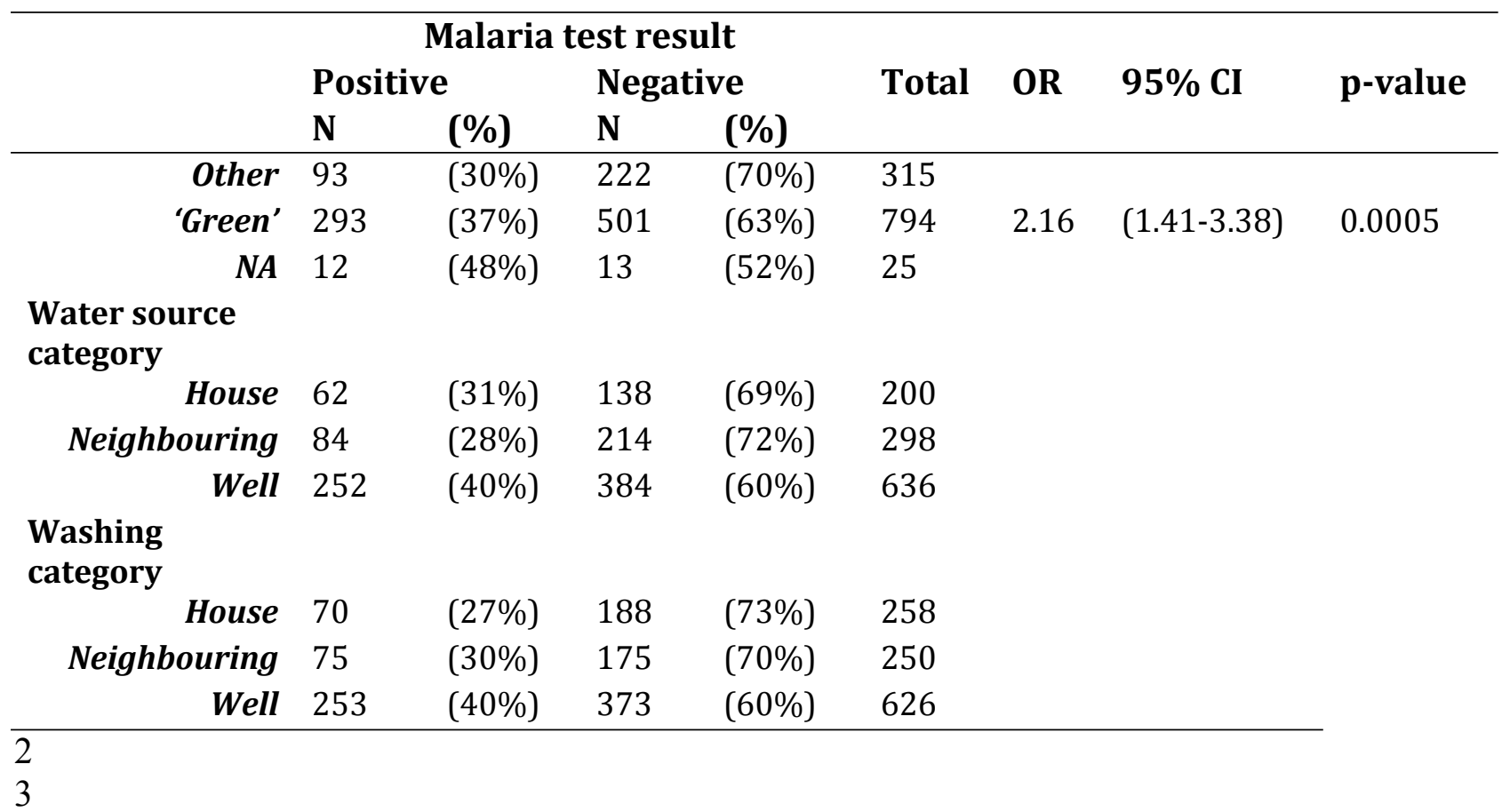


4

Spatial pattern in malaria prevalence

Spatial pattern in malaria prevalence, after accounting for observed risk factors, determined by a Generalised Additive Model (GAM), fitted to the individual-level data. (For details see the supplementary information). 


\section{Linga Linga - Smoothed risk}

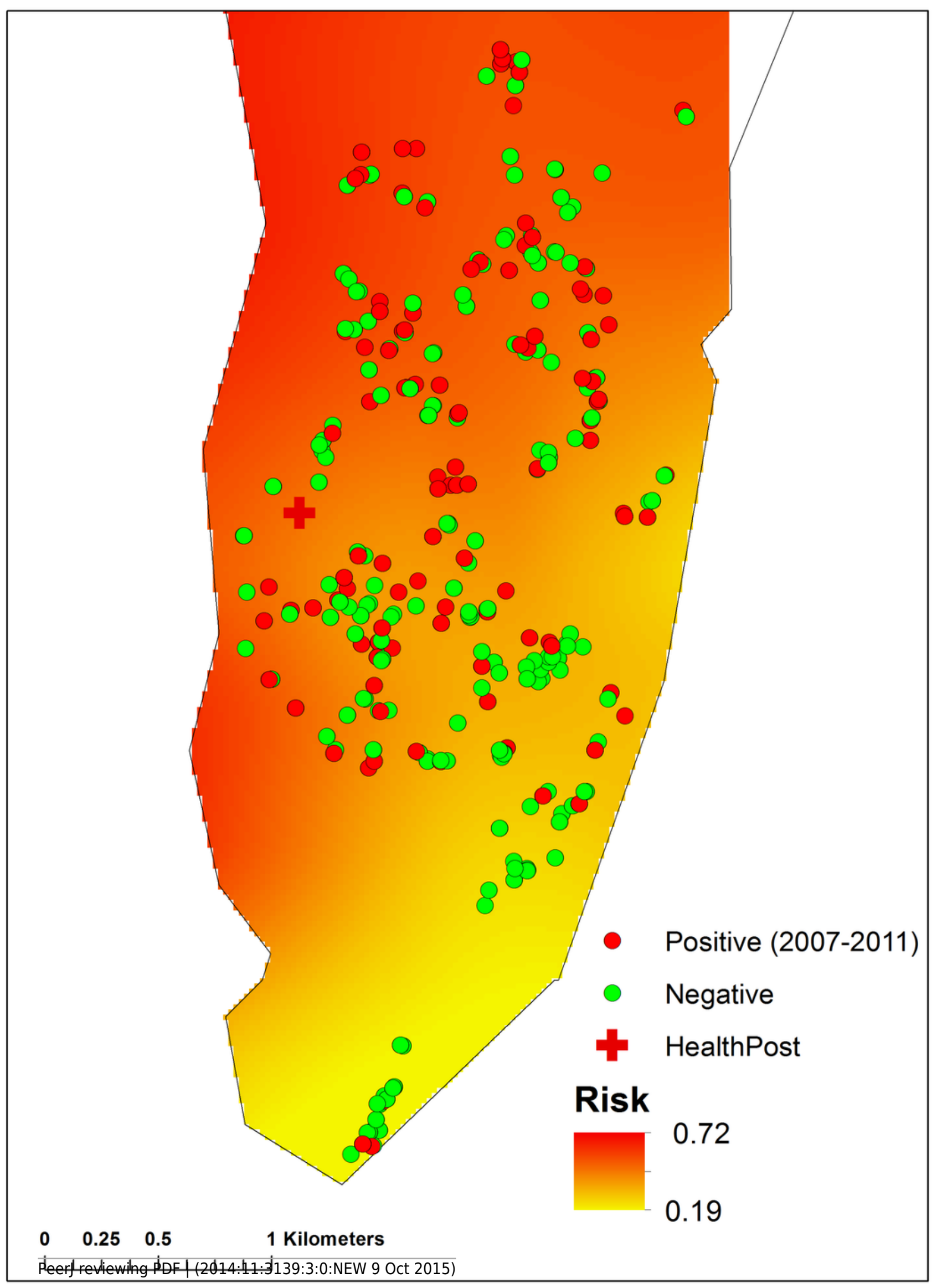




\section{Figure 5 (on next page)}

Malaria incidence among residents, Linga Linga, Mozambique

Incidence among residents - a) fever, b) diagnosed P. falciparum, c) confirmed P. falciparum, d) proportion used net 
PeerJ
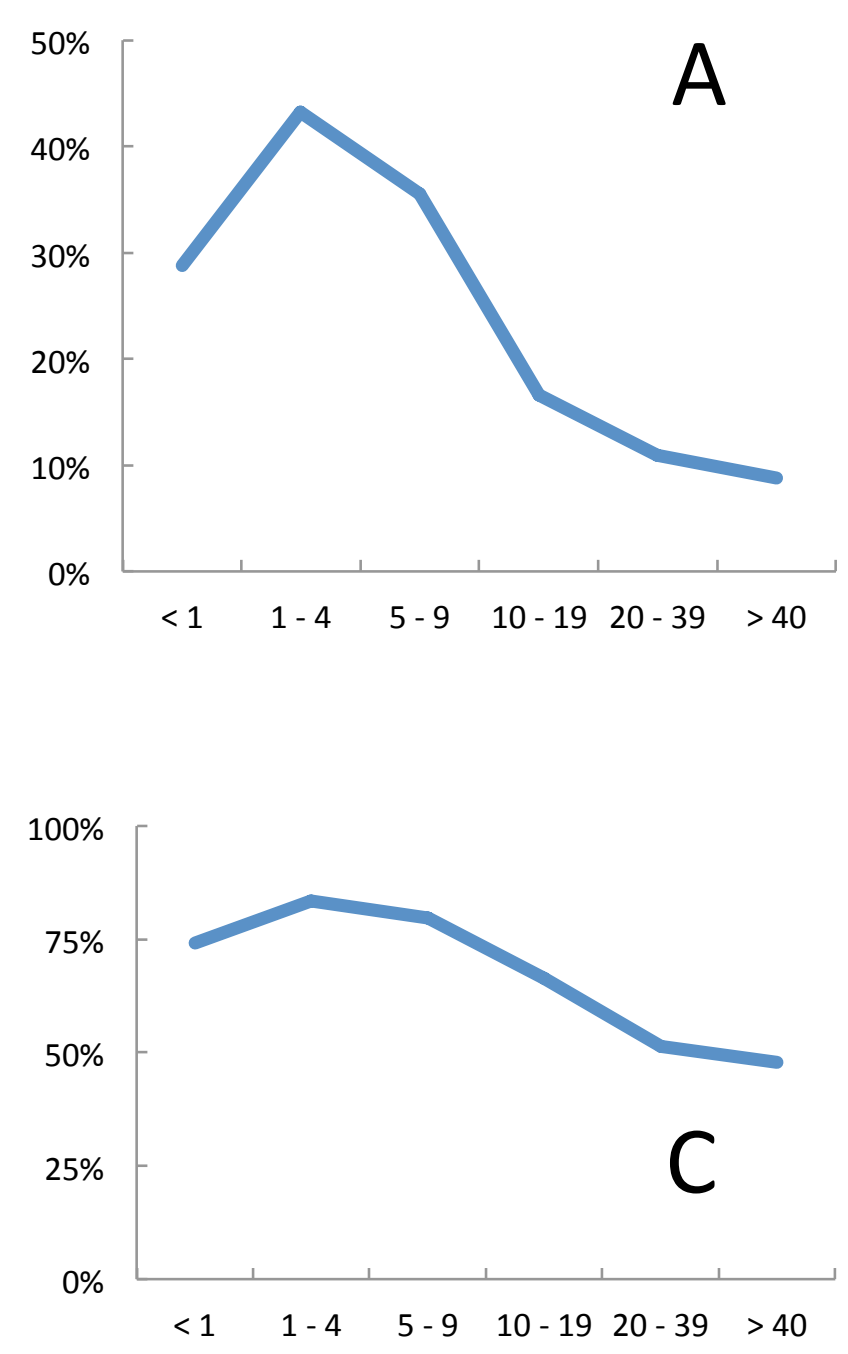
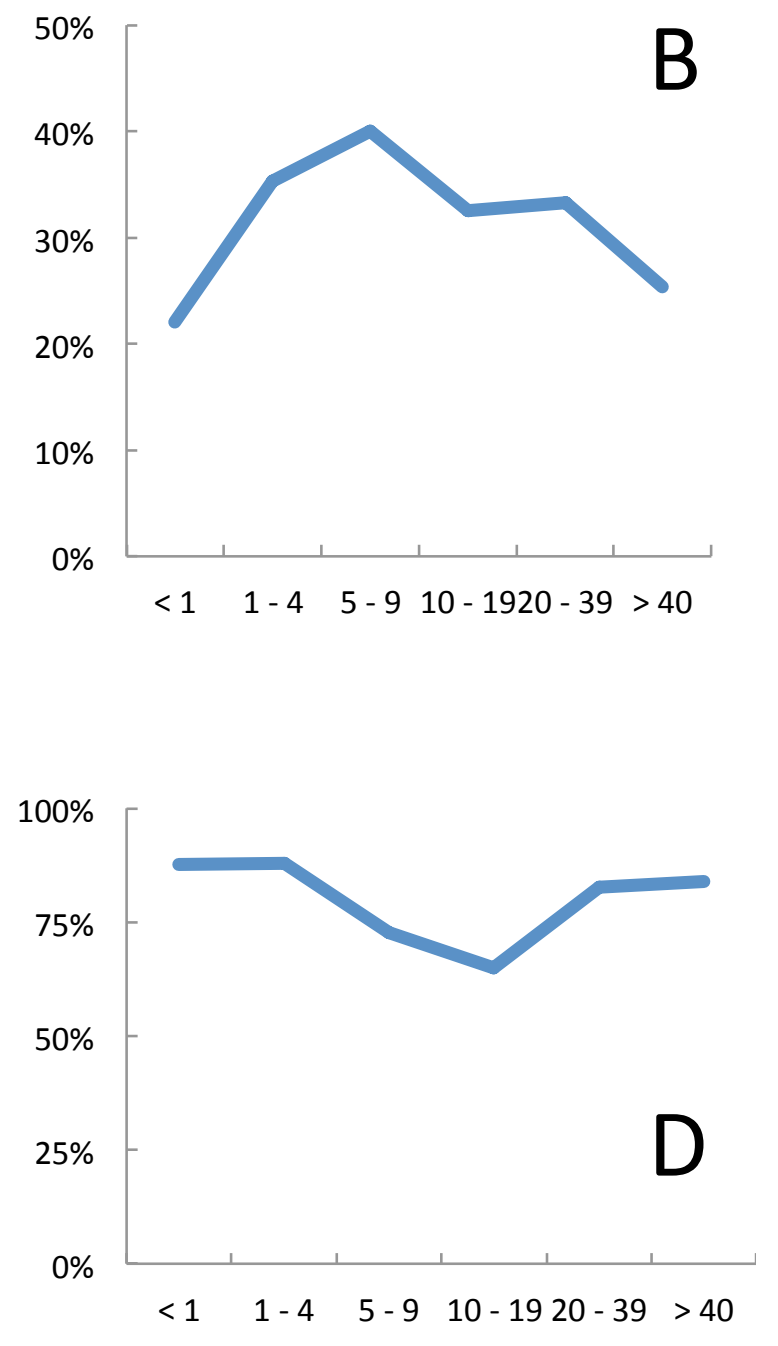

Age in years 
Figure 6 (on next page)

Number of people attending the Linga Linga clinic (2009-2011) reporting symptoms of malaria by sex, age group and positivity

Number of people attending the Linga Linga clinic (2009-2011) reporting symptoms of malaria by sex, age group and positivity 


\section{Males}
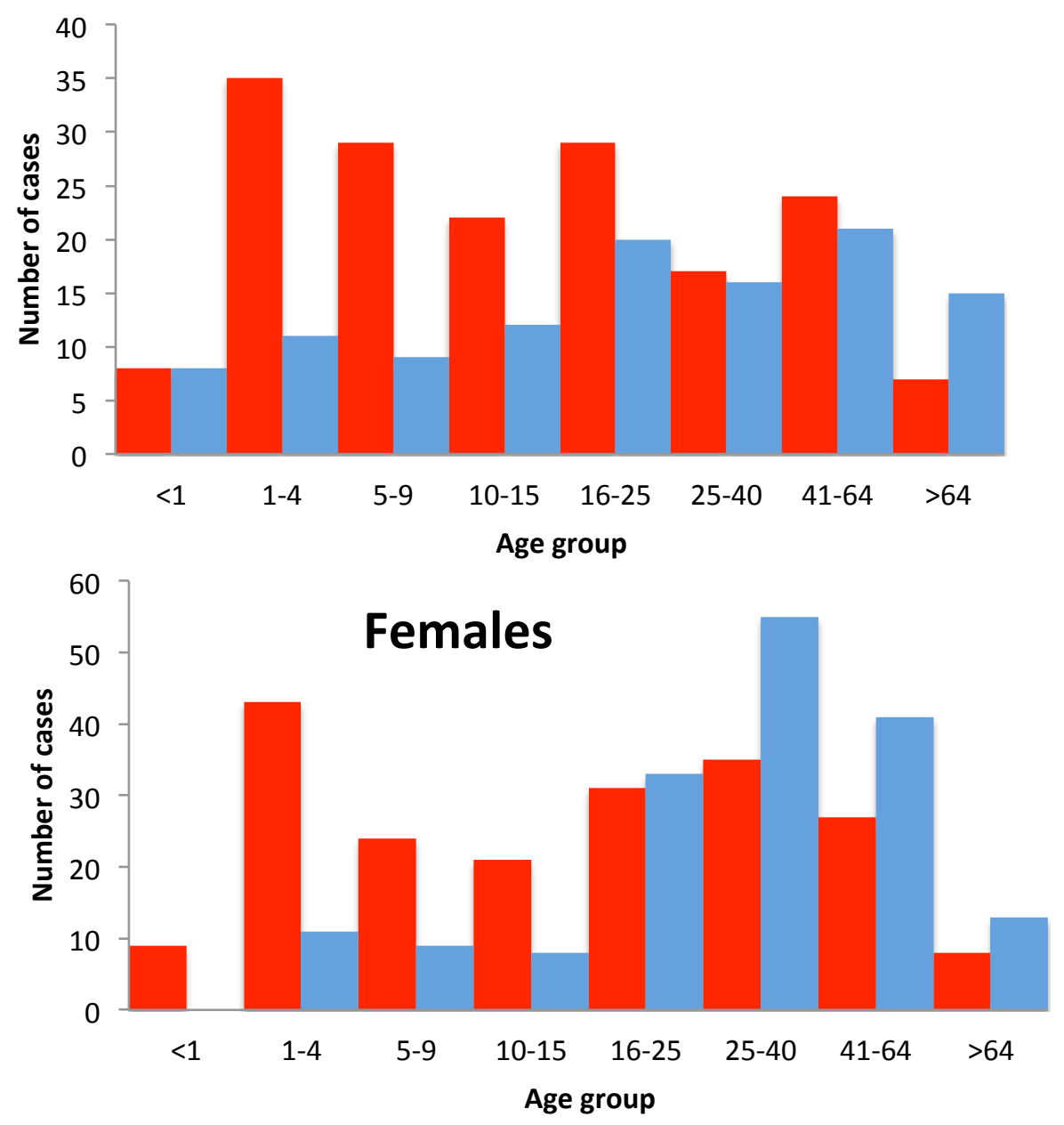

Positive

Negative 
Figure 7 (on next page)

Age dependence of fever and malariological indices: Incidence among visitors, Linga Linga, Mozambique

Age dependence of fever and malariological indices: Incidence among visitors - a) fever, b) diagnosed $P$. falciparum, c) confirmed $P$. falciparum, d) proportion used net 

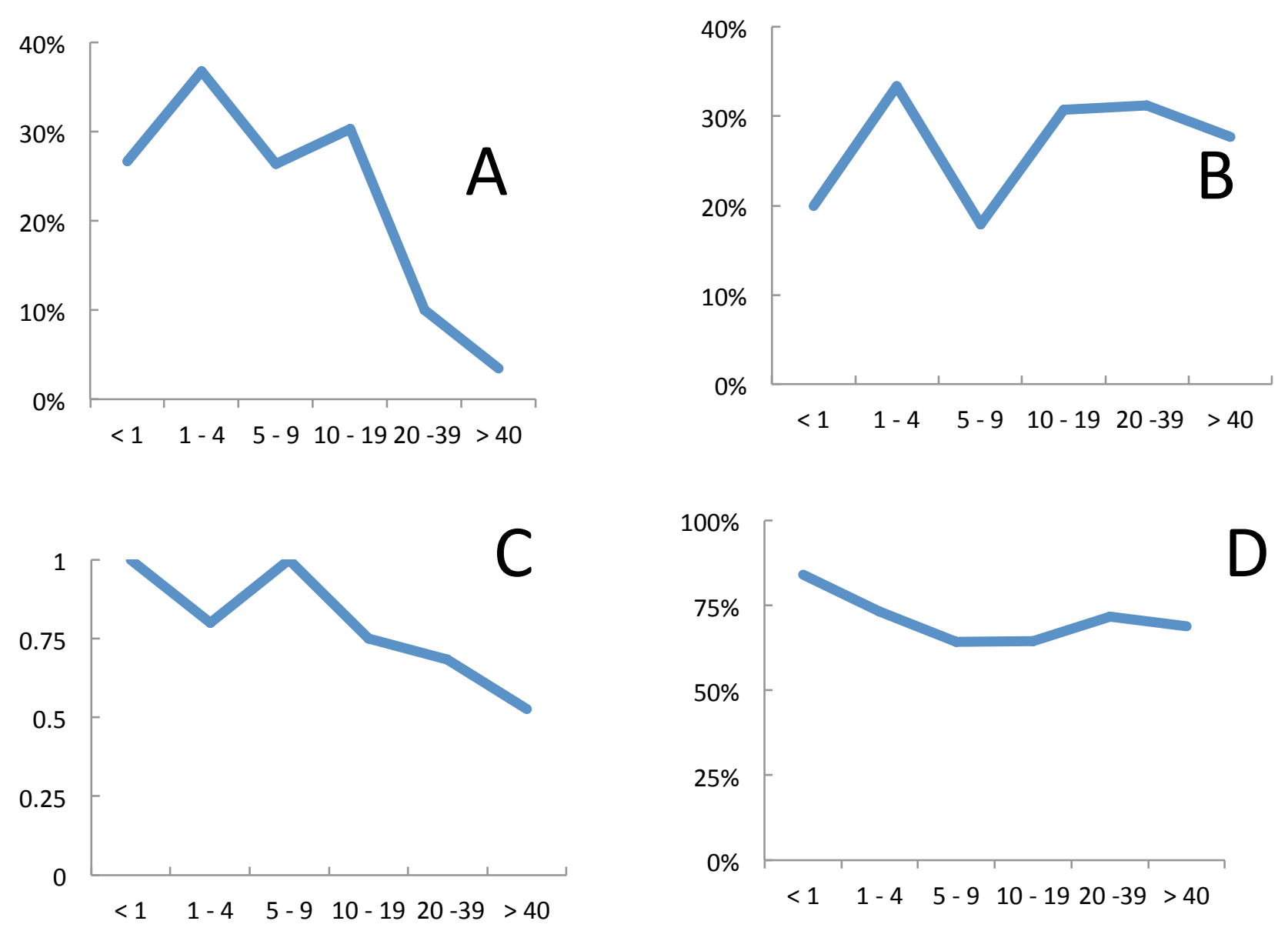

Age in years 


\section{Figure 8 (on next page)}

Seasonality in incidence of diagnosed malaria among resident children below 10 years of age, Linga Linga, Mozambique. 


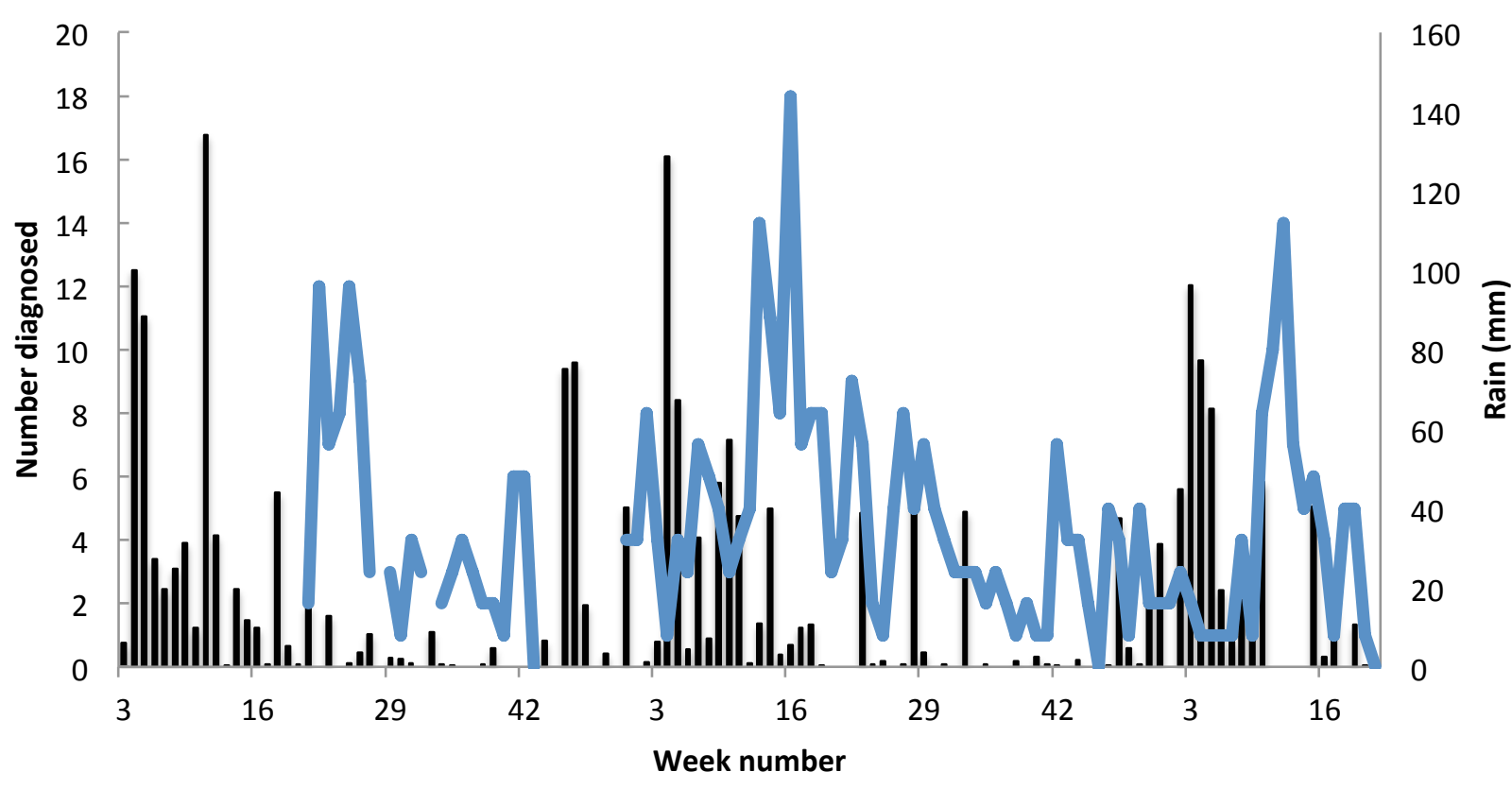

rain $\longrightarrow$-9 years old 
Figure 9 (on next page)

Proportion of resident attendees at the clinic diagnosed with malaria by year and age group, Linga Linga, Mozambique. 


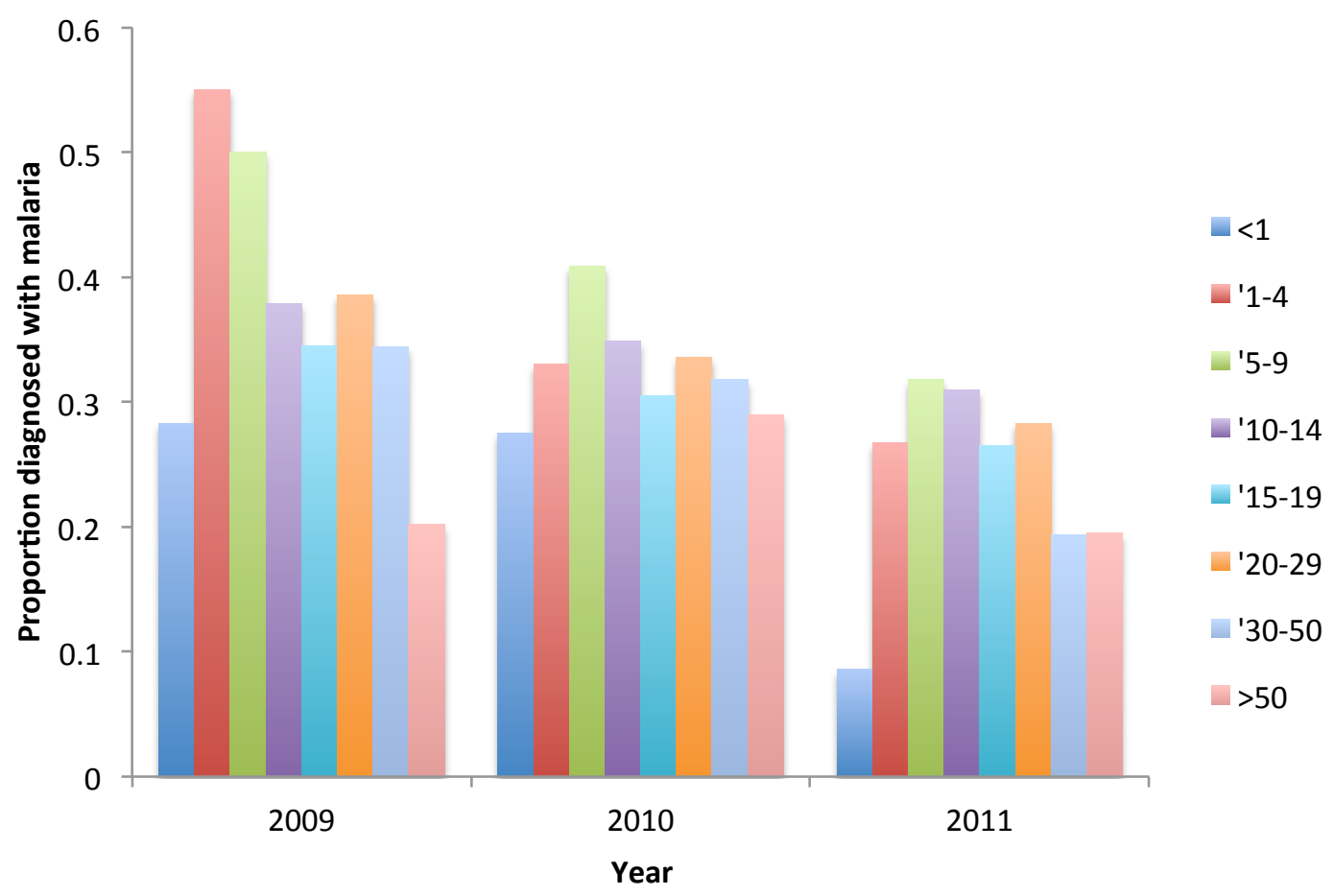


Figure 10 (on next page)

Map of the number of cases of malaria diagnosed at the clinic by household, Linga Linga, Mozambique 


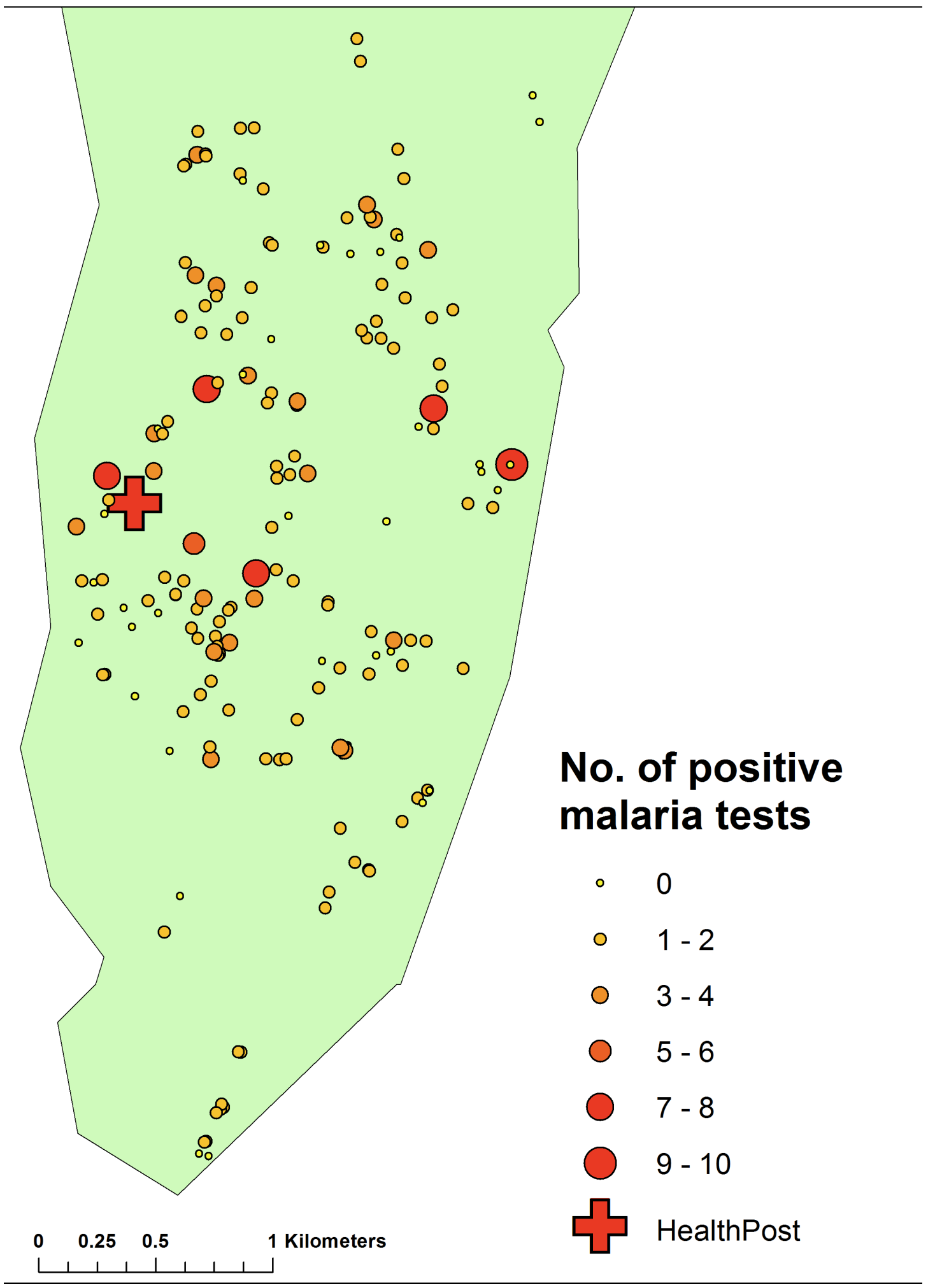

